\title{
The Relationship between the Moso Settlements and the Mani Lumps
}

\author{
Hiromu Ito ${ }^{1} \&$ Wei $\mathrm{Yu}^{2}$ \\ ${ }^{1}$ Faculty of Art and Design, University of Tsukuba, Tsukuba, Japan \\ ${ }^{2}$ Hoshino Resorts Inc., Nagano, Japan \\ Correspondence: Hiromu Ito, Faculty of Art and Design, University of Tsukuba, Tsukuba, Japan, Cooperative \\ Research Building A202, 1-1-1, Tennodai, Tsukuba-shi, Ibaraki 305-8571. Tel: 81-29-853-2825. E-mail: \\ ito.hiromu.fn@u.tsukuba.ac.jp
}

Received: March 11, 2020

Accepted: April 20, 2020

Online Published: June 30, 2021

doi:10.5539/ach.v13n1p1

URL: https://doi.org/10.5539/ach.v13n1p1

\begin{abstract}
The Moso and Nasi minority groups inhabit the area around Lugu Lake, which also includes mani lumps that are associated with nature worship. The setting of the mani lumps differs from one village to another. This study aims to examine the relationship between the characteristics of the Moso settlements and settings of the mani lumps in addition to the functions of each mani lump. The results show that the function of the mani lumps may vary depending on the topography of the settlement, the adjacency between settlements, and the religious facilities in place. Many mani lumps have a view of the Goddess Mountain and may have been established according to the villages' characteristics based on their inherited nature worship beliefs. Lugu Lake is currently undergoing tourism development because of its landscape, and cultural tourism activities based on nature worship with the mani lumps as the centerpiece are expected to be developed.
\end{abstract}

Keywords: Moso Settlements, Mani Lumps, Nature Worship, Setting

\section{Introduction}

\subsection{Background}

The traditional cultures of Chinese minority groups are largely based on the natural environment within which they live. This study explores the relationship between how these Chinese minority cultures perceive their natural environment and their local communities. Thus, nature and culture must be considered as integral and inseparable. The Moso settlements in the Lugu Lake area retain a matrilineal society and have their own unique lifestyle customs. Believing in Tibetan Buddhism and the local Dava religion, the Moso people demonstrate nature worship in their lives and beliefs. In particular, Goddess Mountain, Lugu Lake, and Houlong Mountain, which is at the center of the lake, are revered as "sacred mountains and lakes." Each Moso settlement has a "mani lump," which is a symbol of nature worship and the village inhabitants visit it daily to offer their prayers.

Many previous studies of the Moso culture have focused on its matrilineal social institutions, in addition to the preservation of traditional architecture, settlements, and the natural environment. Huang (2014) used the Lugu Lake area as a case study to reveal the pattern of development in the Hengduan Shan (Transverse Ranges) region in terms of cultural and geographic space. However, few studies have looked at the relationship between culture and nature.

\subsection{Purpose}

The mani lump is a symbol of nature worship; its role within a settlement may vary from settlement to settlement depending on the environment in which the settlements are located and what natural element is being worshipped. The purpose of this study is to clarify the function of the mani lump in each settlement by investigating the locations of the settlement and its mani lump, what can be seen from the mani lump, and to consider how the mani lump should be managed in the future, based on previous studies on nature worship in the Moso settlements in the Lugu Lake region. 


\section{Methodology}

\subsection{Objective Area}

Lugu Lake, which means the "lake deep in the mountains" in the Moso language, is a plateau freshwater lake located between Yongning Township, Ninglang County, and Lijiang City in Yunnan Province, China, and Zhaosho Township, Yangyuan County, Liangshan Yi Autonomous Prefecture in Sichuan Province (Figure 1). Yongning Township was a lodging town at the crossroads of Tibet and the Yunnan and Sichuan provinces. Lugu Lake, which is surrounded by mountains such as Shenshan, has five islands and more than 20 settlements on the lake shore. It is a multiethnic region, with 16 settlements inhabited by the Moso minority (Moso settlements) and one Naxi settlement, and each settlement has its own Shenshan area in the hinterland. The ancestors of the Moso were a nomadic tribe, the Qiang Tribe, who migrated from the north to the south and settled in the Lugu Lake area during the Han Dynasty.

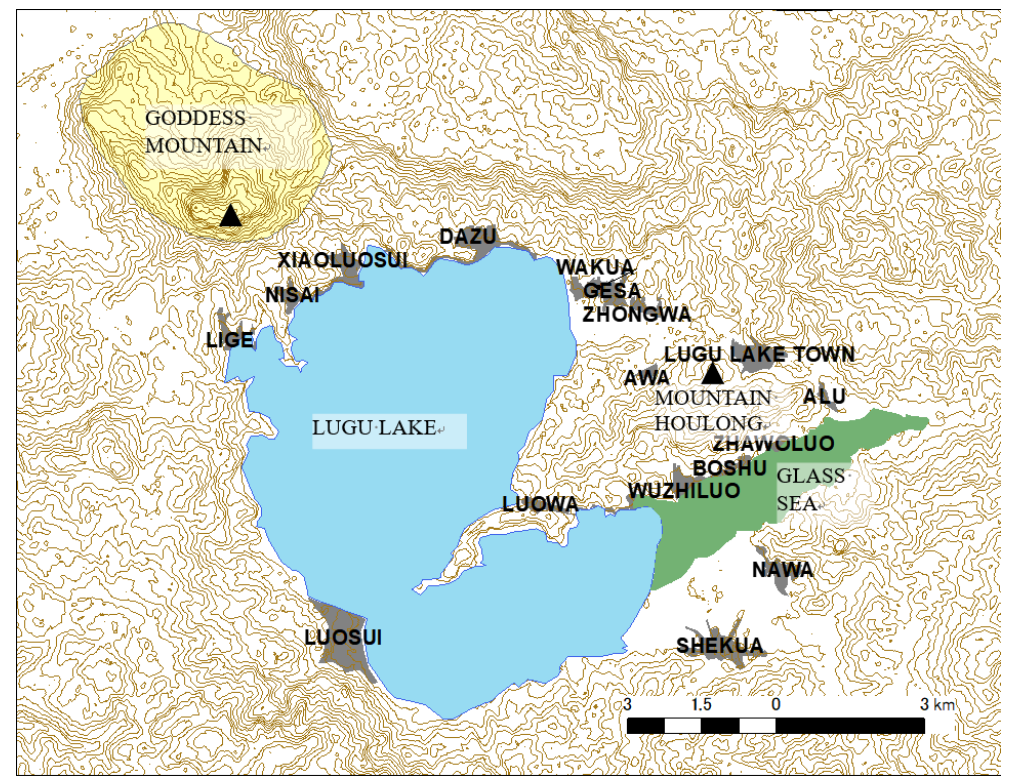

Figure 1. Objective Area

In the Lugu Lake area, the Moso settlements still possess matrilineal clans and traditional customs, such as common-law marriage. The Moso people's religious beliefs are characterized by a dual faith: Davaism, a primitive religion unique to the Moso people, consisting of three parts: ancestor worship, spirit worship, and nature worship, and Tibetan Buddhism, which came to the Lugu Lake area during the Yuan Dynasty (12th century) and replaced Davaism as the leading religion in the 16th century. In Tibetan culture, mountains and lakes are the sacred objects of the local protective gods. Even today, religious rituals using the Shenshan Holy Lake as a sacred place are common on the Tibetan Plateau and its surrounding areas.

\subsection{Method}

Through a literature survey and field interviews, the historical cultures and nature worship at the site were identified, and the religious activities of the people in the area and the function of the mani lumps were summarized in a map.

The location and characteristics of each Moso settlement were then investigated using the map, and the number and arrangement of the mani lumps in each settlement were identified from the field survey. The relationship between nature worship and the function of the mani lumps was discussed with the results of the analysis of the location of the mani lumps.

It was suggested that in the settlements where the Goddess Mountain is the object of worship, the mountain is visible. The visible area of the Goddess Mountain was calculated using ArcGIS to determine if the object of worship was visible from each mani lump at the site of this study. Specifically, we used the ALOS World 3D $30 \mathrm{~m}$ (AW3D30) satellite picture provided by JAXA to obtain the elevation of Goddess Mountain and calculated the visible area of the Goddess Mountain at $500 \mathrm{~m}$ intervals to identify the overlap with each mani lump. 


\section{Results}

\subsection{Faith in the Lugu Lake Area}

In Moso creation mythology, Lugu Lake is deeply related to the Moso people's ancestors and is worshipped as the "Mother Lake." Located in the northern part of Lugu Lake, Goddess Mountain is also called Lion Mountain in the Lugu Lake area because the mountain resembles a lion. Goddess Gam ("Gam" is Tibetan for white lion) was originally a goddess in the Tibetan region and Goddess Mountain and Lugu Lake became objects of worship in the Lugu Lake area after the introduction of Buddhism. In the Moso mythology, Houlong Man Goddess, lover of the goddess Gam, is said to be at Houlong Mountain in the middle of Lugu Lake; thus, Houlong Mountain is also an important object of worship in the Lugu Lake area.

Festivals are held in the Lugu Lake area, such as the Eguo (Tibetan for mountain perimeter) and Xieguo (Tibetan for sea perimeter) festivals, in which the mountain god, lake god, spring god, and female ancestors are worshipped. On the first, fifth, fifteenth, and twenty-fifth days of every month, the Moso people travel along different routes in different settlements by foot, horse, car, or boat to offer songs and dances to the gods. They raise incense at each of the sacred mountains along the lake shore, present offerings to the mountain gods, and pray for peace and happiness. The grandest festival in Lugu Lake area is the Tien Shan festival, which is held on the 25th of the seventh month of the agricultural calendar annually at Goddess Mountain.

\subsection{Origin and Role of Mani Lumps}

Mani lumps (Figure 2) are stones on which spiritual incantations and pictures were written by locals and are a product of Tibetan Buddhism and Tibetan nature worship. In the Lugu Lake region, mani lumps are only found in settlements inhabited by the Moso people who believe in Tibetan Buddhism. They are often found at the entrance of the settlement, in the mountains, at intersections, and by the lake. The Moso people circle around the mani lumps in their settlement several times daily to pray to the gods for peace and a good harvest.

The mani lumps play three main roles for the Moso people, i.e., domain clarification, peace prayers and amulets, and symbols of faith. In domain clarification, the Moso legends describe a local protective deity who built mani lumps to distinguish his domain from other gods. As for peace prayers and amulets, mani lumps were used in primitive Tibetan religions to show reverence for the various gods in the mountains, lakes, forests, and roads that symbolized the heavens, the ground, and the underground. Thus, the gods were enshrined there to prevent the gods and spirits of nature from attacking humans. Finally, as symbols of faith in Tibet, the mani lump is often mountain-shaped and is considered to be the alter-ego of the mountain god. According to an interview with Moso people in the Lugu Lake area, gods of nature such as lake gods and mountain gods are enshrined in the mani lumps to for the Moso to pray to for peace.

In this way, mani lumps are strongly associated with the gods of nature and serve to connect the mountains and lakes, which are symbols and objects of worship, as well as represent them and mark the territory of each settlement.

Table 1. Overview of Moso Settlements

\begin{tabular}{|c|c|c|c|c|c|}
\hline District & Settlement & Terrain & Area (ha) & Adjacent settlements & Note \\
\hline West & Luosui & Flat & 107.1 & $\mathrm{X}$ & \\
\hline \multirow{4}{*}{ North } & Lige & Slope & 23.3 & $\mathrm{X}$ & Disconnected to Lake Rim Road \\
\hline & Nisai & Slope & 19.6 & $\mathrm{X}$ & Foot of Goddess Mountain \\
\hline & Xiao Luosui & Slope & 41.3 & $\mathrm{X}$ & Foot of Goddess Mountain, Sutra Library \\
\hline & Dazu & Slope & 67.4 & $\mathrm{X}$ & Lugu Lake Cliff \\
\hline \multirow{5}{*}{$\begin{array}{l}\text { Northeast } \\
\text { inland }\end{array}$} & Wakua & Slope & 24 & $\mathrm{O}$ & Sutra Library \\
\hline & Gesa & Slope & 23.8 & $\mathrm{O}$ & Ritual Hall \\
\hline & Zhongwa & Slope & 15.6 & $\mathrm{O}$ & Prayer Banner, Entrance to Houlong Mountain \\
\hline & Lugu Lake Town & Flat & 46.1 & $\mathrm{O}$ & Lugu Lake Town Government \\
\hline & Awa & Flat & 7.7 & $\mathrm{X}$ & \\
\hline \multirow{5}{*}{ Grass Sea } & Luowa & Slope & 29.2 & $\mathrm{X}$ & \\
\hline & Wuzhiluo & Flat & 19 & $\mathrm{O}$ & \\
\hline & Boshu & Slope & 17.8 & $\mathrm{O}$ & \\
\hline & Zhawoluo & Slope & 8.6 & $\mathrm{O}$ & \\
\hline & Alu & Slope & 9.1 & $\mathrm{X}$ & Lama Temple \\
\hline \multirow{2}{*}{ South } & Nawa & Flat & 33.9 & $\mathrm{X}$ & \\
\hline & Shekua & Flat & 62.3 & $\mathrm{X}$ & Largest Farmland \\
\hline
\end{tabular}



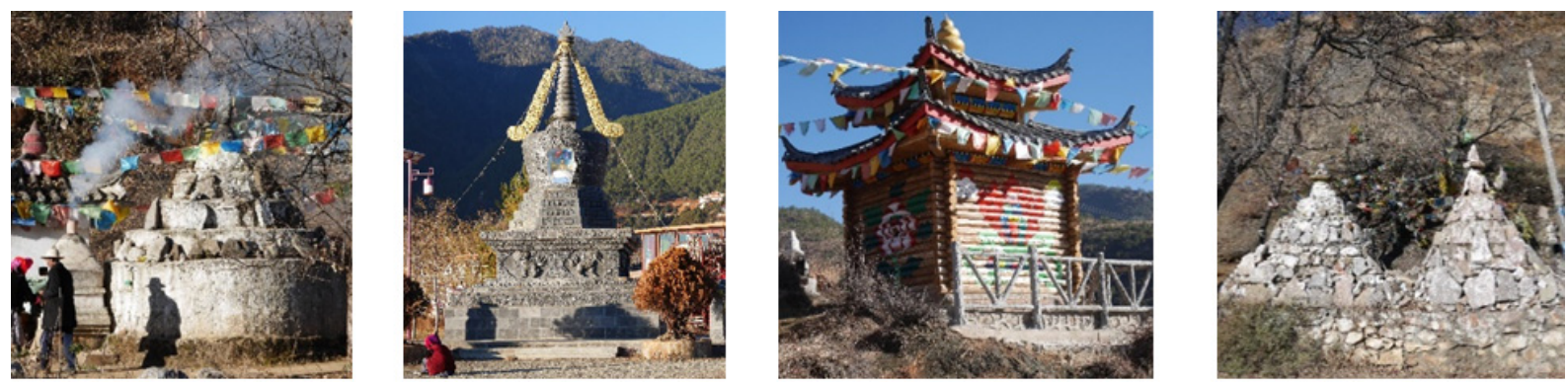

Figure 2. Mani Lumps (Photos by Wei Yu, January 2017)

\subsection{Relationship between Each Moso Settlement and Their Mani Lump}

\subsubsection{Overview of the Moso Settlements}

This investigation was carried out in 16 Moso and 1 Nasi settlements along Lugu Lake (Table 1), 4 in Yunnan Province (all Moso settlements) and 13 in Sichuan Province. Forty-three out of 47 mani lumps in the objective area are located within the settlements, and most of the settlements have more than one mani lump. Three mani lumps outside the settlements were owned by the Moso Museum $(\mathrm{n}=2)$ and a private individual (a hotel owner) $(\mathrm{n}=1)$.

Each settlement is connected to the others by an overland route (along the Lake Rim Road) to the Eguo Festival. The settlements can be broadly divided into western, northern, northeast inland, grass sea, inland, and southern districts. The largest settlement in terms of residential district was Xiao Luosui and the smallest was Awa. The four settlements on the north side of Lugu Lake are all located on slopes facing the lake and are divided by topography. The settlements in the northeast inland area of the lake have several smaller settlements on the slopes and larger settlements on the flats (Lugu Lake Town). Lugu Lake Town Government is located in Lugu Lake Town, and each of the other villages has a sutra library, a ritual hall, a prayer banner, and an entrance to Houlong Mountain. On the north side of the Grass Sea, there are a series of smaller settlements on the slopes, all of which have a harbor. Alu, which is separated from the other settlements, has a lama temple. On the south side of the lake, there are two larger separate settlements on the flat land with large farmlands. In particular, the farmland area of Shekua is the largest in the objective area.

\subsubsection{Setting and Classification of Mani Lumps in the Settlements}

\subsubsection{Settings of Mani Lumps}

A total of 44 mani lumps (Table 2), excluding the Moso Museum and privately owned mani lumps, were classified into five types based on their location within the settlement and their relationship to the road: settlement center, gateway, backside mountain, harbor, and road/lakeside mani lump types. The settlement center mani lump ( $\mathrm{n}=3$ ) was set at the center of the settlement and at the intersection of several roads. The gateway mani lump ( $\mathrm{n}=10)$ was set at the boundary of the settlement, while the backside mountain mani lump $(\mathrm{n}=10)$ was set on the mountain side higher than the settlement. The harbor mani lump $(\mathrm{n}=8)$ was set at a boat landing and the road/lakeside mani lump ( $\mathrm{n}=13)$ was set along the lakeside road that connects the settlements.

In terms of the number of mani lump types, the road/lakeside type was the most common, followed by the backside mountain, gateway, and harbor types. In terms of the number of villages, 8 settlements have the backside mountain and harbor types, 5 settlements have the gateway and road/lakeside types, and 2 settlements have the settlement center type.

\subsubsection{Mani Lump Type by Settlement}

The settlement with the highest number of mani lumps was Dazu on the north side of the lake ( $\mathrm{n}=9$ ), and the settlements with the least number of mani lumps were Wuzhiluo, Zhawoluo, and Alu in the Grass Sea district, and one each in Nawa on the south side of the lake. The combination of mani lump types per settlement was similar in the following districts: west and north side of the lake (Wuzhiluo, Lige, Nisai, Xiao Luosui, and Dazu); northeast inland area of the lake (Wakua, Gesa, Zhongwa, Lugu Lake Town, and Awa), Grass Sea (Luowa, Wuzhiluo, Boshu, Zhawoluo, and Alu), and south side of the lake (Nawa and Shekua). In the settlements west and north of the lake, there were several backside mountain, harbor, and road/lakeside types, especially with more than one road/lakeside type. On the one hand, only Nisai, the closest settlement to Goddess Mountain and the smallest in this area, had a mani lump (backside mountain type) closest to Goddess Mountain and no harbor 
or road/lakeside type. On the other hand, at Xiao Luosui, which, like Nisai, is located at the foot of Goddess Mountain and has a sutra library, there was a mani lump in front of it (road/lakeside type) and no backside mountain type.

Table 2. Settlements and Mani Lump Settings

\begin{tabular}{|c|c|c|c|c|c|c|}
\hline District & Settlement & Settlement Center & Gateway & Backside Mountain & Harbor & Road/Lakeside \\
\hline West & Luosui & & $1(1)$ & $1(1)$ & $1(1)$ & $1(1)$ \\
\hline \multirow{4}{*}{ North } & Lige & & & 1 & 1 & $2(2)$ \\
\hline & Nisai & & & $1(1)$ & & \\
\hline & Xiao Luosui & & 1 & & 1(1) & 1(1) \\
\hline & Dazu & & $1(1)$ & & $1(1)$ & $7(5)$ \\
\hline \multirow{5}{*}{$\begin{array}{l}\text { Northeast } \\
\text { inland }\end{array}$} & Wakua & & $1(1)$ & 1 & & \\
\hline & Gesa & & $2(1)$ & $2(2)$ & & \\
\hline & Zhongwa & & & $1(1)$ & & \\
\hline & Lugu Lake Town & & $2(1)$ & & & \\
\hline & Awa & & 1 & $1(1)$ & & \\
\hline \multirow{5}{*}{ Grass Sea } & Luowa & & & $2(2)$ & 1 & \\
\hline & Wuzhiluo & & & & 1 & \\
\hline & Boshu & & & & 1 & 2 \\
\hline & Zhawoluo & & & & 1 & \\
\hline & Alu & & 1 & & & \\
\hline \multirow{2}{*}{ South } & Nawa & 1 & & & & \\
\hline & Shekua & $2(1)$ & & & & \\
\hline
\end{tabular}

( ) : the number of mani lumps where Mt. Goddess can be visible

There are many road/lakeside mani lumps in Lige-Xiao Luosui-Dazu, where the road is set on a steep slope along the lake, such as Lugu Lake Cliff (Dazu). These settlements are said to have had many mani lumps built to pray for the safety of the waterways and the land because the undulating and winding terrain of these settlements easily blocked sight lines, which results in many traffic accidents and falls into the lake. The relatively large Luosui, Xiao Luosui, and Dazu settlements had mani lumps at the entrance and exit (gateway type), while Xiao Luosui and Dazu also had a harbor on the eastern boundary with a mani lump (harbor type).

The northeast inland settlements do not have harbor and road/lakeside types, but have gateway and backside mountain types. The settlements in this district were adjacent to each other and the gateway type appears to have been established. There was no mani lump at the gateway to Zhongwa, which is surrounded by hills. All settlements in this district except for Lugu Lake Town and Awa have religious facilities with mani lumps at their entrances (backside mountain type). The settlements in this district are adjacent to each other and have mani lumps at the gateway (gateway type). Most of the settlements in this district have backside mountain type mani lumps, while Lugu Lake Town, which had been the administrative center of the region since ancient times, has no mani lumps. This may be because many rulers and aristocrats lived in this town and their method of using mani lumps differs from other settlements. In the Grass Sea district settlements (Luowa, Wuzhiluo, Boshu, Zhawoluo, and Alu), the mani lumps are all located at the settlements' landing areas, which shows the difficulty of the waterway through the Grass Sea. Only in Alu, where the Lama Temple is set, there were no mani lumps except for the gateway type.

In the settlements on the south side of the lake, the mani lumps are only found in the center of the settlement. Only two settlements in this district have mani lumps in the center of the settlement and these two settlements are different in character from the others around Lugu Lake; therefore, the mani lumps are likely to be present accordingly.

\subsubsection{Visibility of Goddess Mountain from the Mani Lumps}

The visibility of Goddess Mountain (Figure 3) for each mani lump type was summarized from the results of the ArcGIS-based calculations of the visible area. Of the 44 mani lumps overall, Goddess Mountain was visible from 26. Backstage mountain type mani lumps had the highest rate of visibility of Goddess Mountain ( 8 out of 10 ), while mani lumps with the lowest rate of visibility were of the gateway (4 out of 10), harbor (3 out of 8 ), and settlement center ( 1 out of 3 ) types. 
The range of visibility of Goddess Mountain differs depending on the settlement and is narrower in the Grass Sea district. In the west, north, and northeast inland districts, the visible area is wide, but Goddess Mountain is not visible from some districts and their mani lumps tend to be set up at the locations where Goddess Mountain is visible.

\section{Discussion}

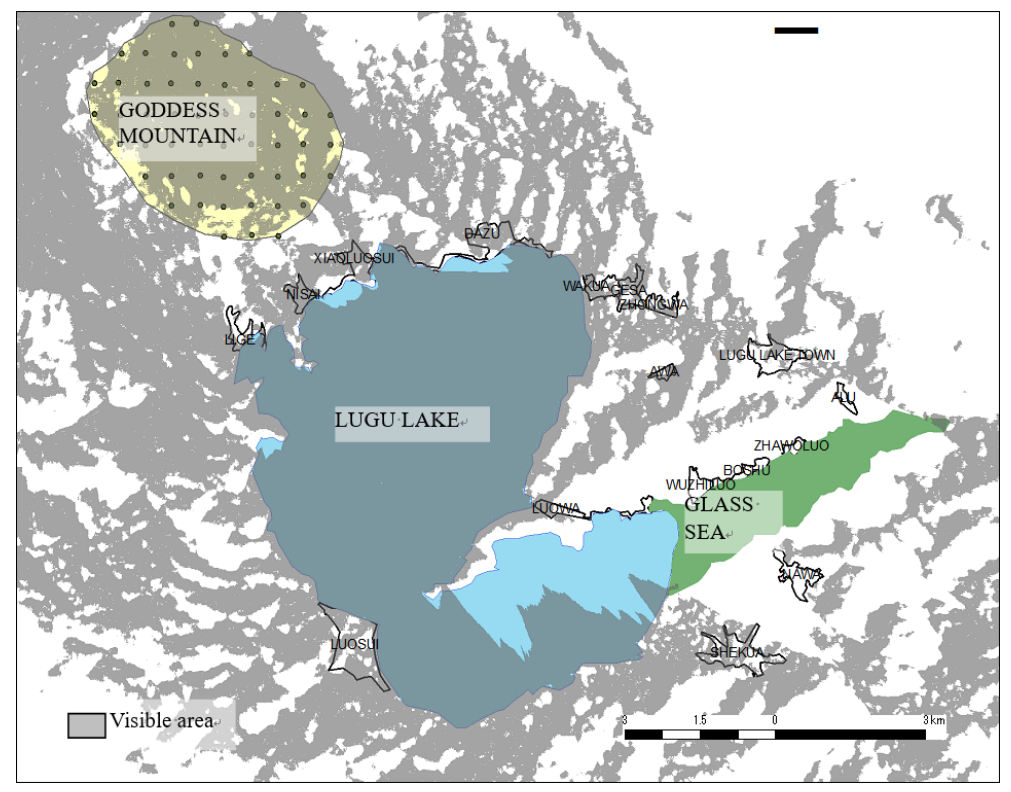

Figure 3. Visible Area of Goddess Mountain

In each Moso settlement, the conditions of the settlements differed by district and were largely centered on the lake. Thus, the mani lump setting type and its visibility of Goddess Mountain differed accordingly. The settlements on the western and northern slopes of the lake were probably established as a traffic safety prayer because of their road/lakeside and harbor type mani lumps, and because Goddess Mountain can be seen from most of these mani lumps. The settlements in the northeastern inland district were probably set up to make the boundaries of the settlements clearer because they are adjacent to each other. There are also many backside mountain type mani lumps with religious facilities in the backside mountain area of each settlement. The fact that the Goddess Mountain is visible from most of the backside mountain type mani lumps suggests that the mani lump was set up as a religious symbol in this area. In the villages of the Grass Sea district, there are harbor mani lumps, which are thought to be a prayer for traffic safety. The Goddess Mountain is visible from the backside mountain type, which is the only one of its kind in this district, which suggests that the backside mountain type is a symbol of faith. The Goddess Mountain is not necessarily visible from the gateway type, which is considered to mainly function as a marker for the settlement's boundaries.

In the southern district, however, mani lumps are only found only in the settlement center, which may differ from the function of the mani lumps described in previous studies. This point will be clarified by studying the process of establishment for Nawa and Shekua settlements in a future study.

Tourism development is currently being undertaken in and around Lugu Lake, with its landscape being the focus of development. As shown in this study, the development of tourism activities based on the unique culture shown in the differences between the different villages and the differing roles of the mani lumps should be considered.

\section{Acknowledgments}

This work was supported by JSPS KAKENHI Grant Number JP 16K08125. We thank Peter Fogarty, MA English 1st Class, from Edanz Group (https://en-author-services.edanzgroup.com/), for editing a draft of this manuscript.

\section{Conflict of interests}

The authors declare that there is no conflict of interests regarding the publication of this paper. 


\section{References}

Akimoto, M., Otsub, H., \& Hori, S. (2003). A study on spatial and scenic relations between Hamlet and Mountain in Murayama Basin, Yamagata Prefecture, Northeast Japan. Journal of The Japanese Institute of Landscape Architecture, 66(5), 565-568. https://doi.org/10.5632/jila.66.565

Charles, M. (2000). Nasi - The kinship system and culture of Mosuo, Yunnan Social Science, Yunnan.

Huang, C. (2013). Evolution of the Human Habitat Environment in the Filtered Lugu Lake Region, China Construction Industry Press, Beigin.

Kanenawa, H. (2007). The Interaction between Tourism and Ethnic Identity in Luguhu, YUNNAN Province of China. Bulletin, Faculty of Foreign Studies, the University of Kitakyushu, (131), 23-59.

Li, J. (2014). Filtered Lugu Lake - Moso Matrilineal Society, Sichuan Nationalities Press, Sichuan.

Ma, C. (1993). A Comparative Study of the Symbols of Ovoo and Manitou, Hulongjiang Ethnic Minorities Series (pp. 106-112). Heilongjiang.

Yum, K. (2013). Tibetan Mountain Gods Beliefs and Regional Social Studies, Lanzhou University.

\section{Copyrights}

Copyright for this article is retained by the author(s), with first publication rights granted to the journal.

This is an open-access article distributed under the terms and conditions of the Creative Commons Attribution license (http://creativecommons.org/licenses/by/4.0/). 